\title{
Influence of Asphaltenes on Gelation of Tetrameric Acid with Calcium Ion at the Oil/Water Interface under Flow-Model Condition
}

\author{
Sébastien SIMON*, Bicheng GAO, Sondre TOFTE, Johan SJÖBLOM \\ Ugelstad Laboratory, Department of Chemical Engineering, the Norwegian University of \\ Science and Technology (NTNU), N-7491 Trondheim, Norway \\ Nicolas PASSADE-BOUPAT \\ TOTAL S.A., PERL - Pôle D’Etudes et de Recherche de Lacq, 64170 Lacq, France \\ Thierry PALERMO, Marianna RONDON -GONZALEZ \\ TOTAL S.A., CSTJF - Centre Scientifique et Technique Jean Féger, 64018 Pau, France
}

Supplementary materials:
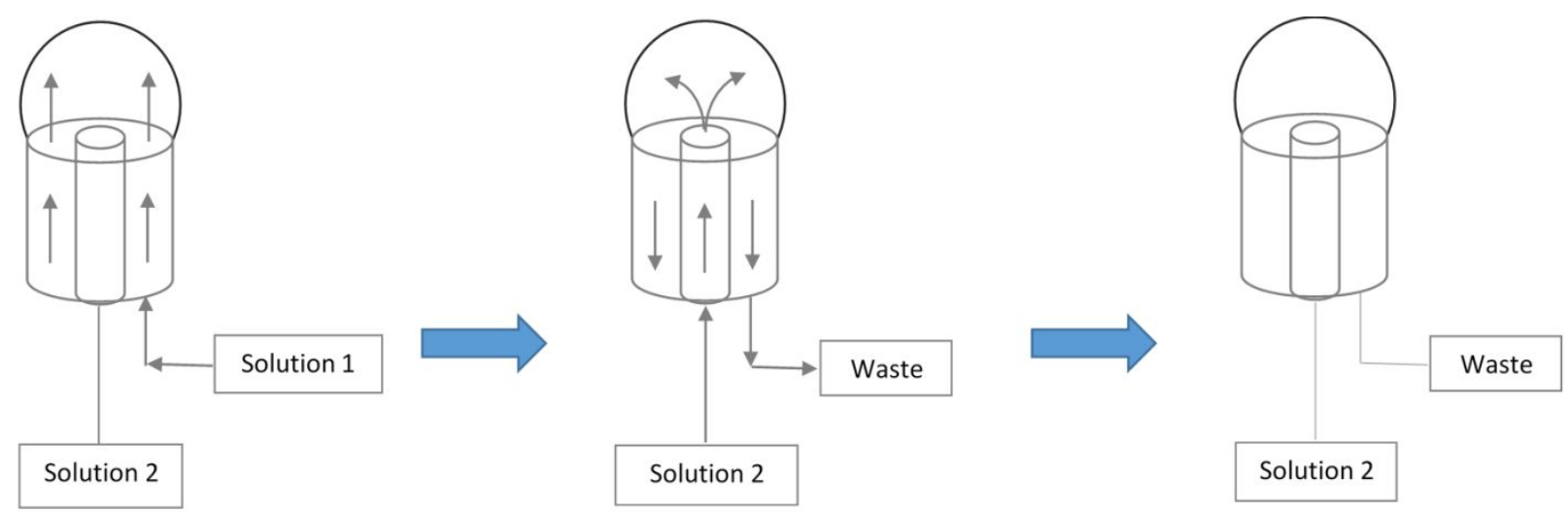

1) Creation of

2) Exchange

the droplet

Figure S1: Schematic pictures of the co-axial capillary device and the procedure to exchange the oil phase inside the droplet. In section 3.1, solution 1=solution 2. In section 3.2, solutions 1 and 2 are different. Adapted from Simon et al ${ }^{1}$. Reproduced with permission. 


\section{$\underline{\text { References: }}$}

(1) Simon, S.; Blanco, E.; Gao, B.; Sjöblom, J.; Passade-Boupat, N.; Palermo, T.; Rondon-Gonzalez, M. Rheological Properties of Gels Formed at the Oil/Water Interface by Reaction Between Tetrameric Acid and Calcium Ion under Flow Condition and at the Batch Scale. Industrial \& Engineering Chemistry Research 2019, 58, 15516. 